\title{
The impact of concurrent pelvic organ prolapse reconstructive surgery on midurethral sling procedure outcome
}

\author{
Buğra Çoşkun ${ }^{1}$, Orhan S. Aksakal ${ }^{2}$, Bora Çoşkun ${ }^{3}$, Engin Yurtçư ${ }^{4}$, Mehmet Özgür Akkurt $^{5}$, \\ Özgül Kafadar ${ }^{1}$, Melike Doğanay ${ }^{2}$ \\ ${ }^{1}$ Sincan Nafiz Körfez State Hospital, Obstetrics and Gynecology Department, Ankara, Turkey \\ ${ }^{2}$ Dr Zekai Tahir Burak Women's Health Research and Education Hospital, Obstetrics and Gynecology Ankara, Turkey \\ ${ }^{3}$ Polatlı State Hospital, Ankara, Turkey \\ ${ }^{4}$ Karabük Research and Education Hospital, Obstetrics and Gynecology Department, Karabük, Turkey \\ ${ }^{5}$ Bursa Şevket Yılmaz Research and Education Hospital, Bursa, Turkey
}

\begin{abstract}
Objectives: To evaluate the effect of concurrent pelvic organ prolapse (POP) reconstructive surgery on midurethral sling (MUS) procedure outcome.

Material and methods: The present retrospective study included 300 women with urodynamically diagnosed stress urinary incontinence that underwent MUS procedures with or without concurrent POP reconstructive surgery. Patients were divided into four groups according to the performed surgery; 1 ) transobturator tape (TOT), 2) TOT with POP surgery (anterior colporrhaphy, posterior colporrhaphy and vaginal hysterectomy), 3) tension free vaginal tape (TVT), 4) TVT with POP surgery. Outcomes of surgeries for each group were evaluated postoperatively at the end of the first and sixth month by performing a cough stress test and also using the Incontinence Impact Questionnaire-7 (IIQ-7) and Urogenital Distress Inventory (UDI-6) questionnaires. Presence of a negative cough stress test was defined as "Cure". Multivariate regression was used to identify the parameters for surgical failure.

Results: Forty-two, 70, 49 and 139 women underwent isolated TOT, concurrent TOT and POP, isolated TVT and concurrent TVT and POP surgery, respectively. Postoperative UDI-6 score and postoperative cure rate were significantly higher in the only TOT group as compared to the TOT + POP group. However, in multiple regression analysis, women's age, parity, body mass index, menopausal status, preoperative urodynamic parameters, MUS types and presence of any concomitant POP reconstructive surgery were found to have no significant effect on surgical outcome.

Conclusions: Concurrent POP reconstructive surgery including anterior colporrhaphy, posterior colporrhaphy and vaginal hysterectomy have no affect MUS procedure outcomes.
\end{abstract}

Key words: concomitant surgery, midurethral sling, outcome, pelvic organ prolapse

Ginekologia Polska 2018; 89, 4: 190-195

\section{INTRODUCTION}

The International Continence Society (ICS) defines urinary incontinence (UI) as"the condition in which the involuntary loss of urine is objectively demonstrable and is a social or hygiene problem" [1]. UI is a public health issue, costing approximately 12.43 billion dollars per year in the US [2].

Stress urinary incontinence (SUI) is defined as the complaint of involuntary leakage of urine upon effort or exertion, or on sneezing or coughing $[3,4]$. Although SUI, the most common type of Ul, may seen in women of all age groups, its incidence steady elevates in later life. The incidence of SUI increases from $2.5 \%$ in nulliparous women to $30 \%$ in menopausal women $[5,6]$.

Pelvic Organ Prolapse (POP) is described as the descending or sagging of the anterior, posterior or top portion (vaginal vault/cervix) of the vagina, solely or all together. The

Corresponding author:

Buğra Çoşkun

Sincan Nafiz Körfez State Hospital, Obstetrics and Gynecology Department, Ankara, Turkey

e-mail: drbugracoskun@gmail.com 
most common etiology includes vaginal birth followed by trauma (chronic constipation, obesity, etc.) increasing the intraabdominal pressure [7]. Although the incidence of POP is not known, around $11 \%$ of women in the US require surgery due to prolapse or incontinence and more than $1 / 3$ of those need reoperation [8].

Since they share similar underlying reasons, urinary and anal incontinence, pelvic organ prolapse and sexual dysfunction may appear together due to loss of pelvic support [9].

Many vaginal and abdominal surgical techniques have been developed for cases of SUI requiring surgical treatment. The most preferred surgical technique is the tension-free vaginal tape (TVT) procedure developed by Ulmsten in 1996 [10]. Various methods have been developed to reduce the complications of this operation, among which we can mention the transobturator tape (TOT) technique developed by Delorme in 2001 [11].

The principal purpose of this intervention is to restore normal function by correcting the impaired anatomy. Since it is thought to share a similar underlying mechanism, currently routine incontinence techniques are proposed to be integrated with prolapse repair [12]. Therefore, the influence of POP repair concomitant with incontinence surgery should be evaluated.

\section{OBJECTIVES}

In this study, we aimed to evaluate the impact of concurrent POP reconstructive surgery (anterior colporrhaphy, posterior colporrhaphy or vaginal hysterectomy) on MUS procedure outcomes in TVT and TOT subgroups.

\section{MATERIAL AND METHODS}

A total of 300 patients diagnosed with SUI and who underwent mid-urethral sling (TOT or TVT operation) surgery between May 2012 and February 2015 at the Ankara Zekai Tahir Burak Women's Health Care Education and Research Hospital, Urogynecology Outpatient Clinic were included in this study.

The study was approved by the local ethics committee of the hospital. Demographic characteristics were noted from patients' files. Patients with a systemic disease (HT, DM, neurologic disorder, etc.) and those without complete follow-up data were excluded from the study. Preoperative urogynecologic examinations included the Baden-Walker Halfway Scoring System for the assessment of POP [13].

The study population was divided into four groups; Group 1, patients who underwent TOT surgery; Group 2, patients who underwent TOT + POP surgery; Group 3, patients who underwent TVT surgery; and Group 4, patients who underwent TVT + POP surgery.
Preoperative urodynamic examination was performed to all patients based on the ICS criteria [7]. Before this examination, complete urinary test and urine cultures were obtained to exclude urinary infection. TOT and TVT operations were performed by the same operating team using general or regional anesthesia (O.A, M.D, B.C). The TOT and TVT technique was performed considering Delorme's description for the outside-in approach [12] and Ulmsten's for the inside-out technique [10], respectively. Type-1 monofilament polypropylene mesh was used for both operations. Moreover, concomitant operations for POP reconstruction and intraoperative complications were noted. Patient records were retrospectively reviewed to determine preoperative, postoperative 1st month and postoperative 6th month satisfaction levels using the Incontinence Impact Questionnaire-7 (IIQ-7) and Urogenital Distress Inventory (UDI-6) survey forms validated for the Turkish language [14]. Negative and positive postoperative stress test was considered as "cure" and "failure", respectively.

Statistical analyses were carried out using SPSS version 22.0 (IBM SPSS, Chicago, IL). Abnormal distribution of the study data required use of independent sample t-test for paired comparison and the study data were expressed as mean \pm standard deviation values. Categorical data were compared with Pearson's chi-square test and the results were expressed as number ( $\mathrm{n}$ ) and percentage (\%). A binary logistic regression model was employed to investigate parameters affecting the cure rate and Odd's ratio was calculated and evaluated. $P<0.05$ was recognized as statistically significant.

\section{RESULTS}

A total of 300 patients were eligible for the study according to our inclusion criteria. The TOT procedure was performed in 112 patients; 42 women without POP and 70 women with POP surgery including colporrhaphy (anterior and/or posterior) ( $n=44)$, and colporrhaphy and concomitant vaginal hysterectomy (VAH) $(n=26)$. Of the 188 patients who underwent TVT and 49 of those without POP. The remaining 139 women underwent TOT with POP surgery including colporrrhaphy (anterior and/or posterior) $(n=106)$ and colporhaphy and concomitant VAH $(n=33)$.

The demographic characteristics of the groups were shown in Table 1. Table 2 shows the intergroup comparison of preoperative, postoperative $1^{\text {st }}$ and $6^{\text {th }}$ month IIQ7 and preoperative, postoperative $1^{\text {st }}$ and $6^{\text {th }}$ month IDU6, and also postoperative $1^{\text {st }}$ and $6^{\text {th }}$ month cure rates. The postoperative $1^{\text {st }}$ month cure rate was significantly higher in Group 1 (90.5\%) than in Group 2 (76.0\%) ( $P=0.04)$. Similarly, Group 4 (88.0\%) had a significantly higher cure rate compared to Group $2(76.0 \%)(P=0.02)$. There was no 
Table 1. Demographic characteristics of the groups

\begin{tabular}{|c|c|c|c|c|c|c|c|c|}
\hline & TOT (n & $=112)$ & & TVT ( $r$ & = 188) & & & \\
\hline & $\begin{array}{l}P O P(-) \\
(n=42) \\
(I)\end{array}$ & $\begin{array}{c}P O P(+) \\
(n=70) \\
\text { (II) }\end{array}$ & P1 & $\begin{array}{l}\text { POP (-) } \\
(n=49) \\
\text { (III) }\end{array}$ & $\begin{array}{c}\text { POP (+) } \\
(n=139) \\
(I V)\end{array}$ & P2 & P3 & P4 \\
\hline Age (years) & $52.0 \pm 9.2$ & $55.0 \pm 9.5$ & 0.05 & $49.0 \pm 9.0$ & $50.0 \pm 8.0$ & 0.90 & 0.20 & 0.00 \\
\hline Vaginal birth (n) & $2.6 \pm 1.4$ & $3.9 \pm 2.3$ & 0.01 & $2.6 \pm 1.4$ & $3.1 \pm 1.3$ & 0.10 & 0.70 & 0.07 \\
\hline BMI $\left(\mathrm{kg} / \mathrm{m}^{2}\right)$ & $29.0 \pm 4.7$ & $29.0 \pm 4.7$ & 0.80 & $30.0 \pm 4.1$ & $30.0 \pm 4.0$ & 0.40 & 0.50 & 0.60 \\
\hline Menopausal status & $21(50.0)$ & $48(68.6)$ & 0.05 & $13(26.5)$ & $50(36.0)$ & 0.10 & 0.01 & 0.00 \\
\hline Smoking & $10(23.8)$ & $6(8.6)$ & 0.02 & $7(14.3)$ & $26(18.7)$ & 0.30 & 0.10 & 0.03 \\
\hline History of macrosomic birth & $8(19.0)$ & $7(10.0)$ & 0.10 & $8(16.3)$ & $27(19.4)$ & 0.40 & 0.40 & 0.05 \\
\hline$\geq$ Grade cystocele & $19(45.2)$ & $66(94.3)$ & 0.00 & $21(42.9)$ & $113(81.3)$ & 0.00 & 0.60 & 0.01 \\
\hline$\geq$ Grade 2 rectocele & $15(35.7)$ & $55(78.6)$ & 0.00 & $16(32.7)$ & $97(69.8)$ & 0.00 & 0.50 & 0.20 \\
\hline$\geq$ Grade 2 descensus & $0(0.0)$ & $26(37.1)$ & 0.00 & $0(0.0)$ & $31(22.3)$ & 0.00 & 0.50 & 0.10 \\
\hline MUCP & $76.4 \pm 31.0$ & $69.1 \pm 22.0$ & 0.10 & $72.0 \pm 53.0$ & $65.0 \pm 22.0$ & 0.20 & 0.60 & 0.20 \\
\hline VLPP & $75.0 \pm 36.0$ & $81.0 \pm 37.0$ & 0.40 & $74.0 \pm 37.0$ & $78.0 \pm 41.0$ & 0.50 & 0.80 & 0.50 \\
\hline
\end{tabular}

Age, vaginal birth, BMI (body mass index), MUCP (Maximum Urethral Closure Pressure) and VLPP (Valsalva Leak Point Pressure) data are shown as mean \pm standard deviation

Menopausal status, smoking, macrosomic birth, cystocele, rectocele and descensus data are shown as $\mathrm{n}(\%)$

$P$ values were calculated by Independent sample t-test and Pearson's chi square test

P1 - probability value between Only TOT and TOT + POP groups

P2 - probability value between Only TVT and TVT + POP groups

P3 - probability value between Only TOT and Only TVT groups

P4 - probability value between TOT +POP and TVT + POP groups

$\mathrm{P}<0.05$ was considered statistically significant

Table 2. Intergroup comparison of postoperative cure rates

\begin{tabular}{|c|c|c|c|c|c|c|c|c|}
\hline & \multicolumn{2}{|c|}{ TOT $(n=112)$} & \multirow[b]{2}{*}{ P1 } & \multicolumn{2}{|c|}{ TVT $(n=188)$} & \multirow[b]{2}{*}{ P2 } & \multirow[b]{2}{*}{ P3 } & \multirow[b]{2}{*}{ P4 } \\
\hline & $\begin{array}{l}\text { POP (-) } \\
(n=42)\end{array}$ & $\begin{array}{l}\text { POP }(+) \\
(n=70)\end{array}$ & & $\begin{array}{l}\text { POP (-) } \\
(n=49)\end{array}$ & $\begin{array}{l}\text { POP (t) } \\
(n=139)\end{array}$ & & & \\
\hline IIQ7 (preoperative) & $15.0 \pm 4.9$ & $14.0 \pm 4.7$ & 0.90 & $15.8 \pm 3.9$ & $14.9 \pm 4.7$ & 0.20 & 0.30 & 0.90 \\
\hline IDU6 (preoperative) & $13.0 \pm 3.0$ & $13.0 \pm 3.9$ & 0.20 & $12.4 \pm 4.3$ & $12.8 \pm 3.4$ & 0.40 & 0.07 & 0.60 \\
\hline IIQ7 (at the end of the $1^{\text {st }}$ month ) & $3.9 \pm 3.1$ & $3.1 \pm 2.2$ & 0.10 & $2.9 \pm 2.6$ & $2.8 \pm 2.7$ & 0.80 & 0.10 & 0.50 \\
\hline IDU6 (at the end of the $1^{\text {st }}$ month ) & $3.4 \pm 2.8$ & $2.5 \pm 1.7$ & 0.04 & $2.6 \pm 2,1$ & $2.9 \pm 2.5$ & 0.40 & 0.10 & 0.30 \\
\hline Cure Rates (at the end of the $1^{\text {st }}$ month) & 90.5 & 76.0 & 0.04 & 92.0 & 88.0 & 0.60 & 0.50 & 0.02 \\
\hline IIQ7 (at the end of the $6^{\text {th }}$ month ) & $2.9 \pm 2.1$ & $2.9 \pm 2.6$ & 0.95 & $2.9 \pm 2.6$ & $2.9 \pm 2.7$ & 0.87 & 0.11 & 0.51 \\
\hline IDU6 (at the end of the $6^{\text {th }}$ month ) & $2.6 \pm 1.9$ & $2.7 \pm 2.3$ & 0.68 & $2.6 \pm 2.1$ & $2.9 \pm 2.6$ & 0.45 & 0.11 & 0.31 \\
\hline Cure Rates (at the end of the $6^{\text {th }}$ month ) & 85.7 & 74.2 & 0.08 & 87.7 & 84.1 & 0.81 & 0.77 & 0.11 \\
\hline
\end{tabular}

UDI6 - Urogenital Distress Inventory 6; IIQ7 - Incontinence Impact Questionnaire 7

Data are shown as mean \pm standard deviation

Cure rates are shown as \%

$P$ values were calculated by Independent sample t-test and Pearson's chi square test

P1 - probability value between Only TOT and TOT + POP groups

P2 - probability value between Only TVT and TVT + POP groups

P3 - probability value between Only TOT and Only TVT groups

$\mathrm{P} 4$ - probability value between TOT + POP and TVT + POP groups

$P<0.05$ was considered statistically significant

statistically significant difference between the groups in terms of postoperative $6^{\text {th }}$ month cure rate. There was also no significant intergroup difference with regard to preoperative IIQ7, postoperative IIQ7, and preoperative IDU6. Only postoperative IUD6 scores were significantly higher in Group 1 than in Group $2(P=0.04)$.
Intergroup comparison of the complication rates is shown in Table 3. A total of 29 (9.6\%) patients developed complications. There was no statistically significant difference between the groups in terms of complication rate $(P=0.35)$. The complications were de novo urge incontinen- 
Table 3. Intergroup comparison of complications

\begin{tabular}{|l|c|c|c|c|c|}
\hline & TOT & TOT + POP & TVT & TVT + POP & P value \\
\hline Complications (+) & $2(4,8)$ & $9(12.9)$ & $8(16.3)$ & $20(14.4)$ & 0.35 \\
\hline De novo urge & $2(4,8)$ & $0(0.0)$ & $3(6.1)$ & $2(1.4)$ & 0.09 \\
\hline Mesh erosion & $0(0.0)$ & $1(1.4)$ & $0(0.0)$ & $1(0.7)$ & 0.74 \\
\hline Hematoma & $0(0.0)$ & $0(0.0)$ & $0(0.0)$ & $1(0.7)$ & 0.76 \\
\hline Bladder injury & $0(0.0)$ & $2(2.9)$ & $2(4.1)$ & $4(2.9)$ & 0.66 \\
\hline Bleeding & $0(0.0)$ & $4(5.7)$ & $1(2.0)$ & $5(3.6)$ & 0.39 \\
\hline Urinary dysfunction & $0(0.0)$ & $2(2.9)$ & $2(4.1)$ & $7(5.0)$ & 0.47 \\
\hline
\end{tabular}

$P$ values were calculated by Pearson's chi square test

Complication data are shown as $\mathrm{n}$ and (\%)

$\mathrm{P}<0.05$ was considered statistically significant

ce in 7 , mesh erosion in 2 , hematoma in 1 , bladder damage in 8 , hemorrhage in 10 , and postoperative urinary dysfunction in 11 patients. No statistically significant difference was determined between the groups in terms of complication rate.

Table 4 shows the logistic regression model of independent factors that may affect the cure at the end of the 1st month. The analysis showed that age, BMI, parity, menopausal status, smoking status, history of macrosomia, preoperative MUCP (Maximum Urethral Closure Pressure), preoperative VLPP (Valsalva Leak Point Pressure), TVT-TOT preference, and presence of anterior colporrhaphy, posterior colporrhaphy and vaginal hysterectomy separately had no effect on cure rate. The same logistic regression analysis for the 6th month cure is shown in Table 5. Similarly, these independent factors such as age, BMI, parity, menopausal status, smoking status, history of macrosomia, preoperative
MUCP, preoperative VLPP, TVT-TOT preference and inclusion of anterior colporrhaphy, posterior colporrhaphy and vaginal hysterectomy individually had no effect on cure rate at the end of the 6 th month.

\section{DISCUSSION}

In our study, concomitant POP reconstructive surgery accompanying MUS operation was found to have no effect on the success of incontinence treatment for short term results. Similarly, neither type of MUS nor presence of POP Surgery was found to have a significant effect on surgical success.

In literature, there is limited data regarding the effect of concomitant POP repair on MUS outcome. In a study conducted by Naidu et al., the patients were categorized into two groups as MUS and MUS + POP surgery groups. A sub-

Table 4. Regression analysis of variables that may influence MUS outcomes at the end of the $1^{\text {st }}$ month

\begin{tabular}{|c|c|c|c|c|c|}
\hline Variable & $\begin{array}{c}\text { Number } \\
(n / n)\end{array}$ & Wald & $\begin{array}{r}\text { Exp } \\
\text { (B) }\end{array}$ & $\mathbf{P}$ & $\begin{array}{r}95 \% \mathrm{Cl} \\
\text { for } \operatorname{Exp} \\
\text { (B) }\end{array}$ \\
\hline Age $(60 y</ \geq 60 y)$ & $61 / 239$ & 0.29 & 0.77 & 0.59 & $0.29-1.98$ \\
\hline TOT / TVT & $112 / 188$ & 3.80 & 0.50 & 0.06 & $0.24-1.00$ \\
\hline Anterior colporrhaphy ( \pm ) & $179 / 121$ & 0.34 & 1.31 & 0.56 & $0.52-3.23$ \\
\hline Posterior colporrhaphy ( \pm ) & $152 / 148$ & 1.28 & 0.62 & 0.26 & $0.27-1.42$ \\
\hline Vaginal hysterectomy $( \pm$ ) & $57 / 243$ & 0.01 & 0.96 & 0.93 & $0.37-2.45$ \\
\hline Body mass index $(30</ \geq 30)\left(\mathrm{kg} / \mathrm{m}^{2}\right)$ & 148/152 & 0.03 & 1.06 & 0.86 & $0.53-2.12$ \\
\hline Parity (n) & - & 0.13 & 0.90 & 0.73 & $0.51-3.21$ \\
\hline Menopausal status ( \pm ) & $132 / 168$ & 0.99 & 0.67 & 0.32 & $0.29-1.48$ \\
\hline Smoking ( \pm ) & $49 / 251$ & 0.55 & 0.68 & 0.46 & $0.24-1.88$ \\
\hline Macrosomic birth $( \pm)$ & $50 / 250$ & 0.04 & 0.91 & 0.85 & $0.35-2.35$ \\
\hline $\operatorname{MUCP}(40<1 \geq 40)$ & $271 / 29$ & 0.05 & 0.88 & 0.83 & $0.281-2.76$ \\
\hline $\operatorname{VLPP}(90</ \geq 90)$ & 104/196 & 0.92 & 1.40 & 0.34 & $0.70-2.80$ \\
\hline
\end{tabular}

MUCP — Maximum Urethral Closure Pressure; VLPP — Valsalva Leak Point Pressure

Values were calculated by Binary Logistic Regression Model

$\mathrm{P}<0.05$ was considered statistically significant 
Table 5. Regression analysis of variables that may influence MUS outcomes at the end of the $6^{\text {th }}$ month

\begin{tabular}{|c|c|c|c|c|c|}
\hline Variable & $\begin{array}{c}\text { Number } \\
(\mathrm{n} / \mathrm{n})\end{array}$ & Wald & $\begin{array}{r}\text { Exp } \\
\text { (B) }\end{array}$ & $\mathbf{P}$ & $95 \% \mathrm{Cl}$ for $\operatorname{Exp}(\mathrm{B})$ \\
\hline 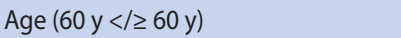 & $61 / 239$ & 0.24 & 0.81 & 0.63 & $0.33-1.93$ \\
\hline TOT/TVT & $112 / 188$ & 2.52 & 0.59 & 0.11 & $0.31-1.13$ \\
\hline Anterior colporrhaphy ( \pm ) & $179 / 121$ & 0.84 & 1.46 & 0.36 & $0.64-3.28$ \\
\hline Posterior colporrhaphy $( \pm$ ) & $152 / 148$ & 1.28 & 0.65 & 0.26 & $0.30-1.37$ \\
\hline Vaginal hysterectomy ( \pm ) & $57 / 243$ & 0.02 & 1.06 & 0.90 & $0.43-2.55$ \\
\hline Body mass index $(30</ \geq 30)\left(\mathrm{kg} / \mathrm{m}^{2}\right)$ & $148 / 152$ & 0.36 & 1.22 & 0.55 & $0.64-2.29$ \\
\hline Parity (n) & - & 0.05 & 1.09 & 0.91 & $0.60-1.9$ \\
\hline Menopausal status ( \pm ) & $132 / 168$ & 0.64 & 0.74 & 0.42 & $0.35-1.54$ \\
\hline Smoking ( \pm ) & $49 / 251$ & 1.82 & 0.50 & 0.18 & $0.18-1.36$ \\
\hline Macrosomic birth $( \pm)$ & $50 / 250$ & 0.04 & 0.92 & 0.84 & $0.39-2.15$ \\
\hline $\operatorname{MUCP}(40</ \geq 40)$ & $271 / 29$ & 0.09 & 1.19 & 0.77 & $0.38-3.66$ \\
\hline VLPP $(90</ \geq 90)$ & $104 / 196$ & 1.19 & 1.42 & 0.28 & $0.75-2.67$ \\
\hline
\end{tabular}

MUCP — Maximum Urethral Closure Pressure; VLPP — Valsalva Leak Point Pressure

Values were calculated by Binary Logistic Regression Model

$\mathrm{P}<0.05$ was considered statistically significant

jective cure was achieved for SUI in $65 \%$ of the MUS group and in $53 \%$ of the MUS + POP treatment group. There was no significance difference considering cure rate among groups [15]. In 2015, Law et al. evaluated the efficacy and outcome of concomitant POP repair during urinary incontinence surgery by comparing 218 women who underwent TOT-TVT operation due to SUI [16]. The patients were split into two groups as the TOT-TVT group and the concomitant prolapse repair (anterior/posterior and/or colporrhaphy and/or vaginal hysterectomy) group. Although the study population underwent two different incontinence surgery (TOT, $(n=124)$ and TVT, $(n=94)$ ), the authors considered as one group regarding similar efficiency of TOT and TVT. TOT-TVT and concomitant pelvic floor repair groups showed no difference in terms of complications, urinary dysfunction, vaginal erosion, and persistent pelvic pain symptoms. The study found concomitant application of pelvic organ prolapse repair during TOT-TVT to be a reliable and effective treatment for SUI. In our study, the complete cure rates for SUI symptoms were $90.5 \%$ and $85.7 \%$ in the isolated TOT group, $76 \%$ and $74 \%$ in the TOT + POP group, $92 \%$ and $88 \%$ in the TVT group, $88 \%$ and $84 \%$ in the TVT + POP group for the 1st month and 6th month after surgery, respectively. Our success rate was relatively higher compared to Naidu et al. and Law et al. This may be associated with better patient selection, use of proper method, and experienced staff. Additionally, we found that concomitant POP repair during MUS surgery did not have any influence on success rate which was consistent with result of previous studies $[15,16]$. Our study had some strengthens including the individual assessment of TOT and TVT groups in terms of concomitant surgery and their short term results.

In the literature, the incidence of complications in Sui operations was reported with a wide range ( $0.3 \%$ to $43.0 \%)$ [17-22]. In the present study, the complications included in descending order of frequency bladder perforation (2.6\%), de novo urgency $(2.3 \%)$, mesh erosion $(0.6 \%)$ and pelvic hematoma (0.3\%). We observed relatively lower complication rate than previous study, probably associated with good patient selection and fine tape fitting, and attentive application of the surgical technique. Naidu et al. reported the rate of bladder perforation ( $1 \%$ vs $1.1 \%$ ), mesh erosion ( $1.5 \%$ vs $1.1 \%)$, and retropubic hematoma ( $0.5 \%$ vs $2.2 \%$ ) in isolated SUI and concurrent SUI and POP surgery, respectively [15]. These results were consistent with our study.

Relatively adequate number of patients, homogeneous patient distribution and use of objective parameters for surgical cure such as quality of life questionnaires were the strengthens of our study. We also assessed the success of concomitant MUS and POP surgery in individual TVT and TOT subgroups.

\section{CONCLUSIONS}

Performing POP reconstructive surgery during MUS operation was found to be a reliable procedure without complications, while having no impact on the success rate of MUS. However, future prospective studies including larger study populations are required to further verify our results.

\section{Acknowledgments}

None. 


\section{Conflict of interest}

Ethic Committee Approval was received for this study. Written informed consent was obtained from patients who participated in this study.

The authors declared no conflict of interest.

The authors declared that this study has received no financial support.

\section{REFERENCES}

1. Gordon D, Gold R, Pauzner D, et al. Tension-free vaginal tape in the elderly: is it a safe procedure? Urology. 2005; 65 (3): 479-482, doi: 10.1016/j. urology.2004.09.059, indexed in Pubmed: 15780359.

2. Jonsson Funk M, Siddiqui NY, Kawasaki A, et al. Long-term outcomes after stress urinary incontinence surgery. Obstet Gynecol. 2012; 120 (1): 83-90, doi: 10.1097/AOG.0b013e318258fbde, indexed in Pubmed: 22914395.

3. Abrams $\mathrm{P}, \mathrm{Cardozo} \mathrm{L}$, Fall $\mathrm{M}$, et al. The standardisation of terminology of lower urinary tract function: report from the Standardisation Sub-committee of the International Continence Society. Neurourol Urodyn. 2002; 21 (2): 167-178, indexed in Pubmed: 11857671.

4. Haylen B, Ridder DDe, Freeman R, et al. An International Urogynecological Association (IUGA)/International Continence Society (ICS) Joint Report on the Terminology for Female Pelvic Floor Dysfunction. Textbook of Female Urology and Urogynecology, Third Edition. 2013: 1090-1105, doi: 10.3109/9781439807217-111.

5. Bing MH, Gimbel H, Greisen S, et al. Clinical risk factors and urodynamic predictors prior to surgical treatment for stress urinary incontinence: a narrative review. Int Urogynecol J. 2015; 26 (2): 175-185, doi: 10.1007/s00192-014-2489-4, indexed in Pubmed: 25248411.

6. Diokno AC, Brock BM, Brown MB, et al. Prevalence of urinary incontinence and other urological symptoms in the noninstitutionalized elderly. J Urol. 1986; 136 (5): 1022-1025, indexed in Pubmed: 3490584.

7. Abrams P, Cardozo L, Fall M, et al. The standardisation of terminology of lower urinary tract function: report from the Standardisation Sub-committee of the International Continence Society. Neurourol Urodyn. 2002; 21 (2): 167-178, indexed in Pubmed: 11857671.

8. Olsen AL, Smith VJ, Bergstrom JO, et al. Epidemiology of surgically managed pelvic organ prolapse and urinary incontinence. Obstet Gynecol. 1997; 89 (4): 501-506, doi: 10.1016/S0029-7844 (97)00058-6, indexed in Pubmed: 9083302.

9. Digesu GA, Chaliha $C$, Salvatore $S$, et al. The relationship of vaginal prolapse severity to symptoms and quality of life. BJOG. 2005; 112 (7): 971-976, doi: 10.1111/j.1471-0528.2005.00568.x, indexed in Pubmed: 15958002 .
10. Ulmsten $\mathrm{U}$, Henriksson $\mathrm{L}$, Johnson $\mathrm{P}$, et al. An ambulatory surgical procedure under local anesthesia for treatment of female urinary incontinence. Int Urogynecol J Pelvic Floor Dysfunct. 1996; 7 (2): 81-86, indexed in Pubmed: 8798092.

11. Delorme E. Transobturator urethral suspension: mini-invasive procedure in the treatment of stress urinary incontinence in women. Prog Urol. 2001; 11 (6): 1306-1313, indexed in Pubmed: 11859672.

12. Maher CM, Feiner B, Baessler K, et al. Surgical management of pelvic organ prolapse in women: the updated summary version Cochrane review. Int Urogynecol J. 2011; 22 (11): 1445-1457, doi: 10.1007/s00192011-1542-9, indexed in Pubmed: 21927941.

13. Baden WF, Walker T. Surgical repair of vaginal defects. Lippincott Williams \& Wilkins 1992.

14. Cam C, Sakalli M, Ay P, et al. Validation of the short forms of the incontinence impact questionnaire (IIQ-7) and the urogenital distress inventory (UDI-6) in a Turkish population. Neurourol Urodyn. 2007; 26 (1): 129-133, doi: 10.1002/nau.20292, indexed in Pubmed: 17083117.

15. Naidu $M$, Thakar $R$, Sultan $A H$. Outcomes of minimally invasive suburethral slings with and without concomitant pelvic organ prolapse surgery. Int J Gynaecol Obstet. 2014; 127 (1): 69-72, doi: 10.1016/j. ijgo.2014.04.017, indexed in Pubmed: 24994496.

16. Law TSM, Cheung RYK, Chung TKH, et al. Efficacy and outcomes of transobturator tension-free vaginal tape with or without concomitant pelvic floor repair surgery for urinary stress incontinence: five-year follow-up. Hong Kong Med J. 2015; 21 (4): 333-338, doi: 10.12809/hkmj144397, indexed in Pubmed: 26183453.

17. Boublil V, Ciofu C, Traxer O, et al. Complications of urethral sling procedures. Curr Opin Obstet Gynecol. 2002; 14 (5): 515-520, indexed in Pubmed: 12401981.

18. Daneshgari F, Kong W, Swartz M. Complications of mid urethral slings: important outcomes for future clinical trials. J Urol. 2008; 180 (5): 18901897, doi: 10.1016/j.juro.2008.07.029, indexed in Pubmed: 18801499.

19. Kobashi KC, Govier FE. Perioperative complications: the first 140 polypropylene pubovaginal slings. J Urol. 2003; 170 (5): 1918-1921, doi: 10.1097/01.ju.0000092403.58592.69, indexed in Pubmed: 14532807.

20. Laurikainen E, Valpas A, Kivelä A, et al. Retropubic compared with transobturator tape placement in treatment of urinary incontinence: a randomized controlled trial. Obstet Gynecol. 2007; 109 (1): 4-11, doi: 10.1097/01.AOG.0000249607.82768.a1, indexed in Pubmed: 17197581.

21. LoTS. Tension-free vaginal tape procedures in women with stress urinary incontinence with and without co-existing genital prolapse. Curr Opin Obstet Gynecol. 2004; 16 (5): 399-404, indexed in Pubmed: 15353949.

22. Ogah J, Cody DJ, Rogerson L. Minimally invasive synthetic suburethral sling operations for stress urinary incontinence in women: a short version Cochrane review. Neurourol Urodyn. 2011; 30 (3): 284-291, doi: 10.1002/nau.20980, indexed in Pubmed: 21412819. 